\section{Who will fill the gap by making nucleic synthesizers now?}

Sir - We would like to draw attention to a looming problem for all those of us doing research involving the chemical synthesis of nucleic acids. Because the main manufacturer has stopped making the equipment we need, we believe that by the end of this year there will no longer be a standard-scale synthesizer manufactured that is really suitable to make DNA or RNA oligonucleotides for research.

Significant areas of RNA research, in particular, require the synthesis of RNA modified in specific functional groups or by the attachment of fluorophores or other reporters. Similarly, antisense oligonucleotide research requires increasingly sophisticated combinations of modified nucleotides and conjugates. For these studies, a research-level synthesizer is indispensable. There will probably be hundreds of laboratories directly affected in the long term, to say nothing of the knock-on effects in the development of the science overall. RNA chemical biology is currently immensely exciting, and moving extremely fast. Yet without the ability to synthesize these molecules at will, the whole field will be very much the poorer.

In our opinion the world leader in the manufacture of DNA/RNA synthesizers has been Applied Biosystems Inc. (ABI). This company produced the venerable 380B and then the 394 research synthesizers. Some time ago it stopped making the 394 synthesizer, and just continued supplying the (in our opinion) inferior Expedite machine. However, it intends to discontinue even that at the end of this year. Thus, although high-throughput machines suitable for preparation of sequencing and PCR primers will still be available, it appears there will be no manufacture of a synthesizer suitable for small-scale, versatile synthesis of nucleicacid analogues.

No doubt many labs will continue to nurse their existing instruments for some time to come, but as wear and tear take their toll and parts eventually fall into short supply we are likely to lose our ability to make the molecules on which so much exciting research depends. Although ABI has an excellent record of maintaining its obsolete synthesizers, it can give no longterm guarantees of this. Further, if no suitable machines are to be manufactured in the future, this prevents imaginative new researchers coming into the field, which will ultimately have a stultifying effect.

We hope this letter will alert everyone interested in the chemical biology of nucleic acids to this very worrying development. We also hope that it might stimulate a manufacturer somewhere to fill this gap. Our hope is that companies that grew big by selling to the research community might remember their origins, and not turn their backs on the people who have come to depend upon them for their research.

David M. J. Lilley*, Michael Gait $\dagger$, Fritz Eckstein $\neq$

${ }^{*}$ CRC Nucleic Acid Structure Research Group, Biochemistry Department, MSI/WTB complex, University of Dundee, Dow Street, Dundee

DD1 5EH, UK

$\dagger$ MRC Laboratory of Molecular Biology, Hills Road, Cambridge CB2 2QH, UK

$\$$ Abteilung Chemie, Max-Planck-Institut für Experimentelle Medizin, Hermann Rein Strasse 3, D-37077 Göttingen, Germany

\section{Outbreak needs lab tests and clinical diagnosis}

Sir - Your welcome News report on 12 April (Nature 410, 727; 2001), that the UK foot-and-mouth disease epizootic may be slowing, referred to an article two weeks earlier (Nature 410, 501; 2001). This reported that three independent groups of researchers had told the UK government that rapid slaughter of infected animals was the best way to slow the outbreak.

Without wishing to detract from the valuable contributions being made by epidemiologists, most veterinary clinicians and pathologists dealing with farm animals were aware of this need even before the outbreak started. The need for rapid diagnosis and speedy implementation of control measures for diseases of this type is part of their basic training.

Early delays in dealing with the current outbreak were significantly influenced by owners of diseased animals not requesting veterinary advice quickly enough, possibly because the clinical signs of foot-andmouth disease, particularly in sheep, can be difficult even for a responsible and observant owner to detect. Another cause of early delay was the requirement to have animals produced for commercial purposes valued - not an issue when dealing with an epizootic in laboratory mice.

At the beginning of an epizootic it is essential to diagnose the disease correctly and identify the causal agent by laboratory tests, to provide epidemiologists with accurate information for mathematical models. In some cases it can take as long as four days to declare a sample positive for foot-and-mouth disease virus.

Once the aetiology of the disease is known, control procedures can be implemented more quickly by relying on diagnosis based on clinical signs, and laboratory tests are not needed. The effectiveness of this approach depends on the diagnosis being made by people who, in the case of foot-and-mouth, can distinguish between the lesions of this disease and those of the other enzootic diseases prevalent in the United Kingdom such as mucosal disease, bovine papular stomatitis, contagious pustular dermatitis, foot rot and laminitis.

Hugh M. Pirie

North East Corner, Buchanan Castle Estate, Drymen, Glasgow G63 OHX, UK

\section{Fossil hunters in dispute over Ethiopian sites}

Sir - Your News story "Restrictions delay fossil hunts in Ethiopia" (Nature 410, 728; 2001) omitted to report some of the things I told your reporter during our conversation at the American Association of Physical Anthropology meeting in March.

First, the Ethiopian authorities granted me a palaeoanthropological permit last year for the Gadamaitu region, which includes Galili. My team did not displace Yohannes Haile Selassie from this site: his permit was for the Mulu Basin area, which does not overlap with the Galili area. I offered him both cooperation and the opportunity to continue his work with my team in our permit area, but he refused both offers.

Second, when I applied in March 2000 for the second time for a permit for exactly the same site, the Centre for Research and Conservation of Cultural Heritage in Addis Ababa gave me a permit for the Gadamaitu/Galili region for the next three years. If Yohannes Haile Selassie had already held a valid permit for this area, I would not have obtained mine from the issuing authorities.

Third, Ethiopia is a proud, independent country and its authorities are fully capable of writing rules and regulations protecting its cultural heritage. These rules should be respected by foreign scientists; to ask, as your reporter did during our interview, if I had something to do with formulating these regulations is an insult both to me and to Ethiopia.

Ethiopia is working hard at improving democracy and is willing to open its doors to the international scientific community through these new regulations, which I personally fully support.

\section{Horst Seidler}

Institute for Anthropology, Althanstr. 14, 1090 Wien, Austria

We stand by the facts as reported in our story - Editor, Nature. 